\title{
Numerical modelling and experimental investigation on welding residual stresses in large-scale tubular K-joints
}

\author{
C. ACEVEDO ${ }^{1}$, J. M. DREZET ${ }^{2}$ and A. NUSSBAUMER ${ }^{1}$ \\ ${ }^{1}$ ICOM Steel Structures Laboratory, EPFL, Lausanne, Switzerland, ${ }^{2}$ LSMX Computational Materials Laboratory, EPFL, Lausanne, Switzerland
}

Received in final form 29 May 2012

A B STRACT This paper is devoted to the experimental and numerical assessment of residual stresses created by welding in the region surrounding the weld toe of tubular K-shaped joints (i.e. region most sensitive to fatigue cracking). Neutron-diffraction measurements were carried out on K-joints cut from large-scale truss beams previously subjected to high cycle fatigue. Tri-axial residual stresses in the transverse, longitudinal and radial direction were obtained from the weld toe as a function of the depth in the thickness of the tube wall. In addition, thermomechanical analyses were performed in three-dimensional using ABAQUS and MORFEO finite element codes. Experimental and numerical results show that, at and near the weld-toe surface, the highest residual stresses are critically oriented perpendicularly to the weld direction, and combined with the highest externally applied stresses. Based on a systematic study on geometric parameters, analytical residual stress distribution equations with depth are proposed.

Keywords fatigue; finite element modelling; residual stress; thermomechanics; welded joint.

NOMENCLATURE $D=$ outside chord diameter

$d=$ outside brace diameter

$T=$ chord wall thickness, temperature

$t=$ brace wall thickness

$g=$ gap distance between the brace outer walls at the chord crown toe

$\beta=$ diameters ratio $d / D$

$\gamma=$ chord slenderness $D /(2 T)$

$\tau=$ wall thickness ratio $t / T$

$\zeta=$ normalized gap parameter $g / D$

$\theta=$ brace angle

\section{INTRODUCTION}

Modern steel tubular road bridges are most often composed of welded trusses with K-shaped joints; however, these joints are susceptible to fatigue under traffic loading. ${ }^{1}$ Fatigue cracks typically develop in the gap region, at the weld toe in between the tubes forming the K-joints, ${ }^{2,3}$ even though this is not the only location where the hot spot stresses reach local maximas. A detrimental combination of applied stress concentrations, ${ }^{4-6}$ residual stresses ${ }^{7}$ and imperfections ${ }^{8,9}$ induced by welding explains why cracks often initiate in the vicinity of the weld toe even

Correspondence: C. Acevedo. E-mail: claire.acevedo@a3.epfl.ch under compressive loads. Currently, there is lack of data concerning the three-dimensional (3D) residual stresses in these joints.

Residual stresses were defined by Gurney ${ }^{10}$ as 'locked-in stresses that exist in a body or a part of a body in the absence of any externally applied load'. Created by thermally induced deformations during welding, high tensile residual stresses are present in the gap area between braces of the K-joints. Combined with welding imperfections acting as crack initiators, the residual stress field has a strong influence on the onset of crack propagation. ${ }^{11-14}$

Several techniques exist to evaluate residual stresses (sectioning, layer removal, hole-drilling, X-ray, etc.) but the depth of measurement is small and/or the method is 
destructive. Neutron-diffraction is a powerful and reliable method to measure non-destructively $3 \mathrm{D}$ residual strains from the surface until $15 \mathrm{~mm}$ depth in a complex geometry. ${ }^{15-17}$ Note that even if this method is not destructive in the area of measurement, it may be necessary to cut a window far from this area to minimize loss of neutrons through matter before reaching their target. In this investigation, neutron-diffraction measurements were conducted in the gap region of $\mathrm{K}$-joints to evaluate the residual stress field along the usual position of the crack path and in its surroundings.

Residual stresses can also be predicted using a 3D thermomechanical finite element (FE) model. Some aspects of the problem were simplified to improve the simulation efficiency. Numerical simulations were performed with the FE code ABAQUS and the welding and manufacturing oriented code MORFEO (Manufacturing Oriented Finite Element tOol).

The first objective of this study was to assess, experimentally and numerically, welding residual stresses to understand how residual stresses are distributed in Kjoints. Once the numerical results were experimentally validated, the second objective was to propose residual stress distribution equations based on a systematic $\mathrm{FE}$ study on different geometric configurations.

\section{NEUTRON-DIFFRACTION EXPERIMENTAL PROCEDURE}

\section{Test samples}

Experimental investigations to characterize the stress field induced by the welding process were conducted on tubular $\mathrm{K}$-shaped joints, as shown in Fig. 1, cut-out from largescale truss beams. A slow cutting with an electric saw equipped with a cooling system was used. A maximum stress relaxation of $20 \mathrm{MPa}$ was measured by strain gauges after cutting. Moreover, for neutron-diffraction measurement purpose, windows were cut in the other side of the tube, without affecting stresses in the zone of interest, to prevent significant attenuation of the neutron beam.

The truss beams were $9 \mathrm{~m}$ long by $2 \mathrm{~m}$ high and were subjected to constant amplitude high-cycle fatigue. They were made of non-alloyed ferritic structural steel (mild steel) $\mathrm{S} 355 \mathrm{~J} 2 \mathrm{H}$. The designation $\mathrm{S} 355 \mathrm{~J} 2 \mathrm{H}$ is used for a structural steel $(\mathrm{S})$ with a minimum yield stress value of $355 \mathrm{MPa}$ for a nominal thickness $t \leq 16 \mathrm{~mm}$ and a minimum toughness of $27 \mathrm{~J}$ at $-20{ }^{\circ} \mathrm{C}(\mathrm{J} 2)$. In this case, a tubular hollow section $(\mathrm{H})$ is required.

Investigated joints were fabricated and welded under the same conditions as real bridges by a steel manufacturer. This is essential to reproduce welding imperfections and residual stresses induced by welding. The K-joint was composed of part of the chord with two brace branches

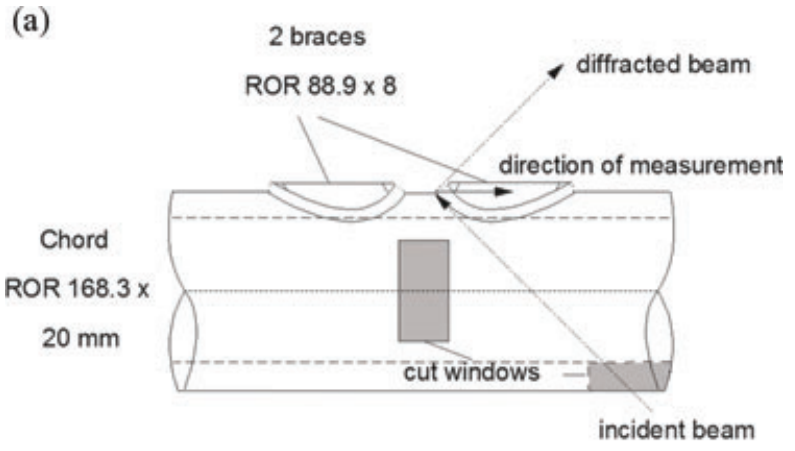

(b)

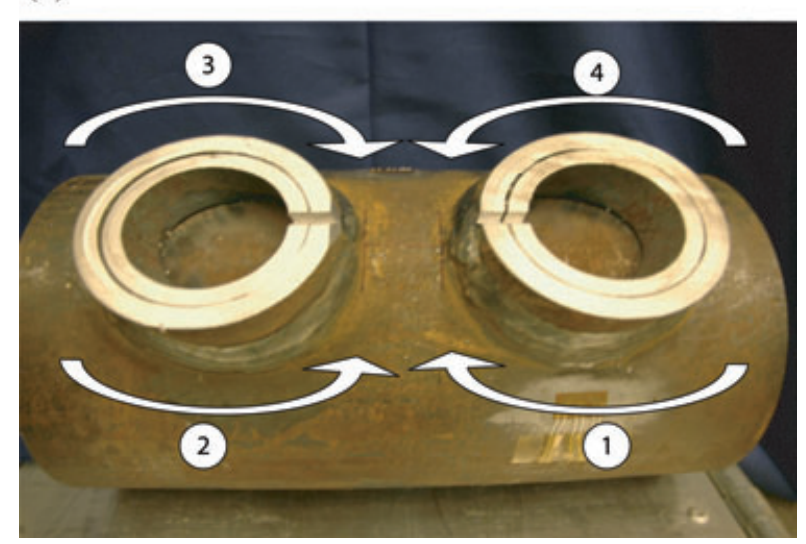

Fig. 1 (a) Schematic of the K-shape welded joint and its dimensions in $\mathrm{mm}$, (b) the welding sequence of one pass.

welded onto it leaving a gap distance $g$ between brace outer walls to prevent overlapping (see Fig. 1). The chord wall had a thickness $T$ of 20 with an outside diameter $D$ of $168.3 \mathrm{~mm}$; braces had a thickness $t$ of $8 \mathrm{~mm}$ and an outside diameter $d$ of $88.9 \mathrm{~mm}$.

A flux cored arc welding MAG 136 process using electrode Filarc $1.4 \mathrm{~mm}$ was employed in accordance to AWS A5.20:E71 T-1. ${ }^{18}$ The welding torch was moved by the welder from the crown heel to the crown toe with a travel speed of $5.5 \mathrm{~mm} \mathrm{~s}^{-1}$. The welding current and the arc voltage were respectively set to $270 \mathrm{~A}$ and $30 \mathrm{~V}$. Seven weld passes were necessary to ensure full penetration. Each pass consisted of a sequence of four welding steps with intermediate cooling as illustrated in Fig. 1(b). A welding step lasted $25 \mathrm{~s}$ and a cooling step lasted $125 \mathrm{~s}$, except the last which lasted $9000 \mathrm{~s}$ to ensure the complete cooling. The heat source is moving around the weld from the crown heel to the crown toe following a 3D bicylindrical curve (intersection curves of two cylinders which are oblique in that case).

The crack growth was monitored on several joints with a system using alternating current potential drop. It was seen from the fatigue tests that tensile residual stresses in $\mathrm{K}$-joint gap region are sufficiently high to enable crack 
propagation even under compressive applied stresses. Description and results are detailed by the authors in a paper devoted to fatigue tests. ${ }^{19}$

\section{Neutron-diffraction measurements}

Experimental investigations using neutron-diffraction were performed with the diffractometer SALSA [Institut Laue-Langevin (ILL), France] to evaluate the triaxial residual strain state deep inside samples taken from the truss specimens. ${ }^{20}$ Neutron-diffraction measurements ${ }^{15-17}$ were carried out on non-cracked K-joints within the truss beams.

Neutron-diffraction is used to provide the accurate lattice spacing $d$ of the atomic structure. Under stress, this spacing $d$ increases. Knowing the stress-free lattice spacing $d_{0}$, the elastic strain can be calculated by $\varepsilon=(d-$ $\left.d_{0}\right) / d_{0}$. Stresses can be deduced from strains using the generalized Hooke's law.

When diffraction occurs, the $d$ spacing can be obtained using the Bragg's law $n \lambda=2 d \sin \theta$, where $n \lambda$ is a multiple of the wavelength $\lambda, d$ is the lattice spacing and $2 \theta$ is the diffraction angle. To determine $d$ with the monochromatic strain diffractometer SALSA at ILL, the wavelength $\lambda$ is fixed to $1.64 \AA$ (ferritic steel with a diffraction angle around $90^{\circ}$ ) and the diffraction angle is measured.

The $d_{0}$ spacing was measured on stress-free reference samples machined with a diamond blade through the chord wall thickness. It has shown to be the same in the three principal directions and through the thickness. For ferritic steel such as $\mathrm{S} 355 \mathrm{~J} 2 \mathrm{H}$ steel, strains were measured with the (211) diffracting plane as recommended by the Versailles Project on Advanced Materials and Standards VAMAS standard ${ }^{17}$ because this plane is weakly affected by intergranular strains and present a similar behaviour to that of the bulk. A gauge volume of $2 \times 2 \times 2 \mathrm{~mm}^{3}$ has been chosen to measure with sufficient statistics within a short period of time.

The orientation of the sample was particularly challenging to measure strains in the gap between the brace weld toes through the wall thickness. Because of complex shape of the joint, it was difficult to prevent the incidentdiffracted neutron beam from entering twice the tube wall and consequently from exceeding the path length limit of $60 \mathrm{~mm}$. Therefore, windows were cut in the tube away from the region of the weld (Fig. 1a). The plane of measurement presented in Fig. 2 was chosen because it has been shown by previous fatigue tests ${ }^{19}$ that crack always initiate at the weld toe in the gap region perpendicular to this plane It was found using the hole-drilling method that maximum tensile residual stresses are oriented in the transverse direction ( $X$-axis). The sample was reoriented in order that the bisector between the incident and the diffracted neutron beam coincided with the transverse

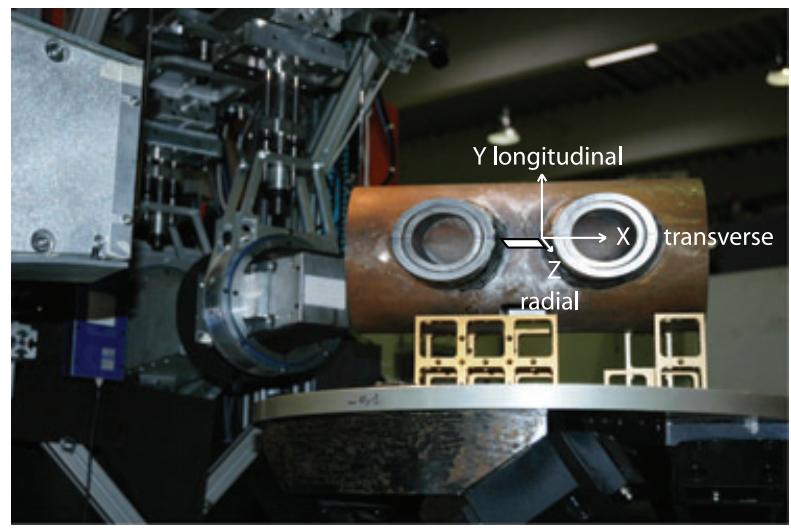

Fig. 2 Plane of neutron-diffraction measurement through the thickness of the tube wall. Strains are measured in three directions (transverse $X$, longitudinal $Y$ and $\operatorname{radial} Z$ ).

(dir. $X$ perpendicular to the weld toe), longitudinal (dir. $Y$ parallel to the weld toe) and radial (dir. $Z$ in depth) directions as indicated in Fig. 2. Large quantities of neutron diffraction ND data points are measured allowing for drawing residual stress maps for these three directions.

\section{THERMOMECHANICAL FEM MODEL}

Numerical analyses were performed to simulate 3D residual stress distributions using FE method in the $\mathrm{K}$-joint presented in chapter 2. Uncoupled thermomechanical FE analyses were employed to predict the temperature field (transient heat transfer), and the induced stress field (see Fig. 4).

The following assumptions in the welding modelling, inspired by Refs. [21] and [22], were intended to generate a model able to simulate rapidly and efficiently residual stresses while providing quality results:

- A 3D FE analysis was used to accurately predict heating/cooling of welding sequences and avoid the overheating effect induced in two dimensions.

- An uncoupled thermomechanical FE formulation was chosen to solve the problem. The metallurgical aspects are neglected for this type of mild steel, except for the heat release because of phase transformations which is taken into account in the thermal cycle. Dong and Hong ${ }^{21}$ has shown that, for mild carbon steel, residual stress variations because of martensitic transformation are small and localized around the heat-affected zone. Because these transformations create local compression residual stress of approximately $5 \%$ of the total residual stresses, neglecting them is a conservative assumption.

- The seven-pass welding was simulated as a single pass with an equivalent heat source. As recommended by Lindgren ${ }^{22}$ to obtain the most accurate results in merging passes, the 
heat input that corresponded to the total heat input of the seven weld passes was used. In ABAQUS, a spherical heat source was used whereas in MORFEO, a truncated circular cone model was employed. The heat source was composed of a volumetric flux moving on the weld path at a speed of $5.5 \mathrm{~mm} \mathrm{~s}^{-1}$ (real welding speed). To verify the effect of the simplification in one single pass, an intermediate validation of the model consisted to control that the computed size of the weld pool matches the one measured by optical macrography. It has shown that the spherical heat source used with ABAQUS gave a fusion profile which is closer to reality than the truncated circular cone. It might also be explained by the better energy conservation in ABAQUS as it controls the temperature variation and the time step. Metal deposition is not considered, the FEs representing the weld were present in the model from the beginning.

- Plastic strains accumulated in the fusion zone are cancelled when the temperature is greater than the solidus temperature (*ANNEAL TEMPERATURE option in ABAQUS) to ensure that there is no unrealistic residual stresses induced by a plastic strain accumulation at each of the four welding steps of a pass.

- The thermal analysis was formulated in terms of heat conduction, heat losses by radiation and convection and heat input simulating the welding source. Latent heat of fusion was also considered using a value of $247000 \mathrm{~J}(\mathrm{~kg}$ $\left.{ }^{\circ} \mathrm{C}\right)^{-1} \cdot{ }^{23}$ To consider the convection flow in the weld pool, an artificial increase in the thermal conductivity by three times was introduced above the melting temperature of the steel. ${ }^{24,25}$ Thermal properties (thermal conductivity, material density, specific heat) taken from the Eurocode 3 recommendations on structural fire design ${ }^{26}$ are given in Fig. 3 as a function of temperature.

- The mechanical analysis was based on an elasto-plastic model with linear isotropic work hardening ignoring rate-dependent (creep) effects at high temperatures. Temperature-dependent mechanical properties required to solve the mechanical problem are the Young's modulus and the Poisson's ratio for elastic strains, the yield stress and the stress-plastic strain evolution for plastic strains and the thermal expansion coefficient for thermal strains. These mechanical properties ${ }^{27}$ are summarized in Fig. 3.

Two codes were chosen to perform thermomechanical analyses: ABAQUS ${ }^{\circledR 28}$ and MORFEO $^{\circledR} \cdot{ }^{29}$ ABAQUS presents large analysis capabilities (nonlinear, transient, dynamic, etc.) whereas MORFEO is rather dedicated to welding and manufacturing (Manufacturing Oriented Finite Element tOol; MORFEO).

The thermal and mechanical analyses were performed using 8-node linear hexahedral elements (i.e. heat transfer elements for the thermal analysis and stress/displacement (a)

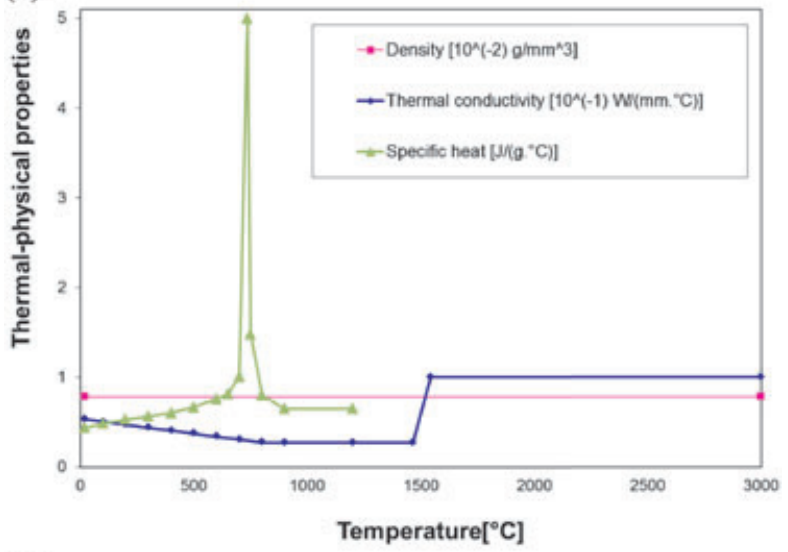

(b)

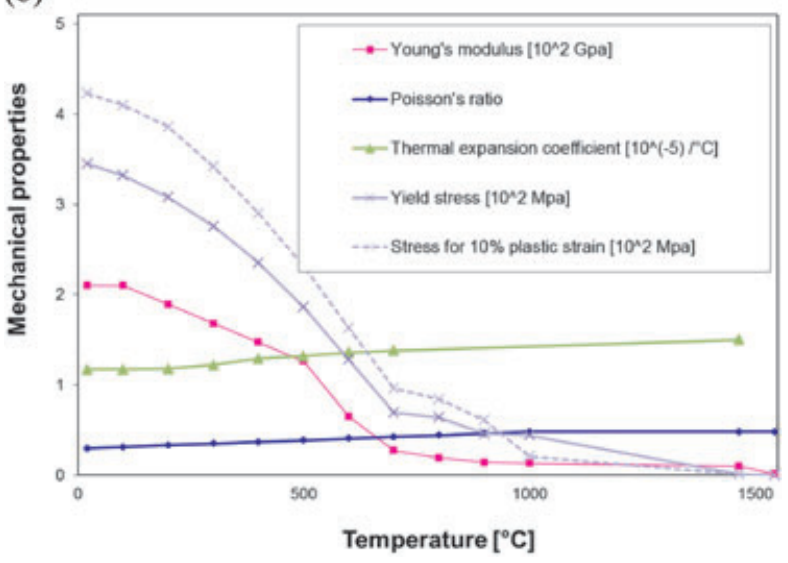

Fig. 3 Temperature-dependent thermal properties (a) and mechanical properties (b) for steel S355.

elements for the mechanical analysis). Convergence studies have shown that a $2 \times 2 \times 5 \mathrm{~mm}$ mesh size in the gap region with a linear interpolation is a good compromise to obtain sufficiently accurate residual stress results $(20 \%$ difference with a mesh of $1 \times 1 \times 2.5 \mathrm{~mm}$ or a quadratic interpolation) within an affordable computation time (nine times faster than for the mesh of $1 \times 1 \times 2.5 \mathrm{~mm}$ ). To obtain enough computed data points close to the surface, the size of the mesh was increased from $1.25 \mathrm{~mm}$ at surface to a maximum of $4.5 \mathrm{~mm}$ in depth. The chosen mesh was identical for thermal and mechanical analyses (see Fig. 4), and comprised 48549 elements and 53966 nodes.

\section{EXPERIMENTAL VERSUS NUMERICAL RESULTS}

Figure 5 presents the transverse (along $x$ ) residual stress maps obtained by neutron-diffraction (Fig. 5c), and simulated with ABAQUS (Fig. 5a) and with MORFEO (Fig. 5b). These result maps were obtained also in the 


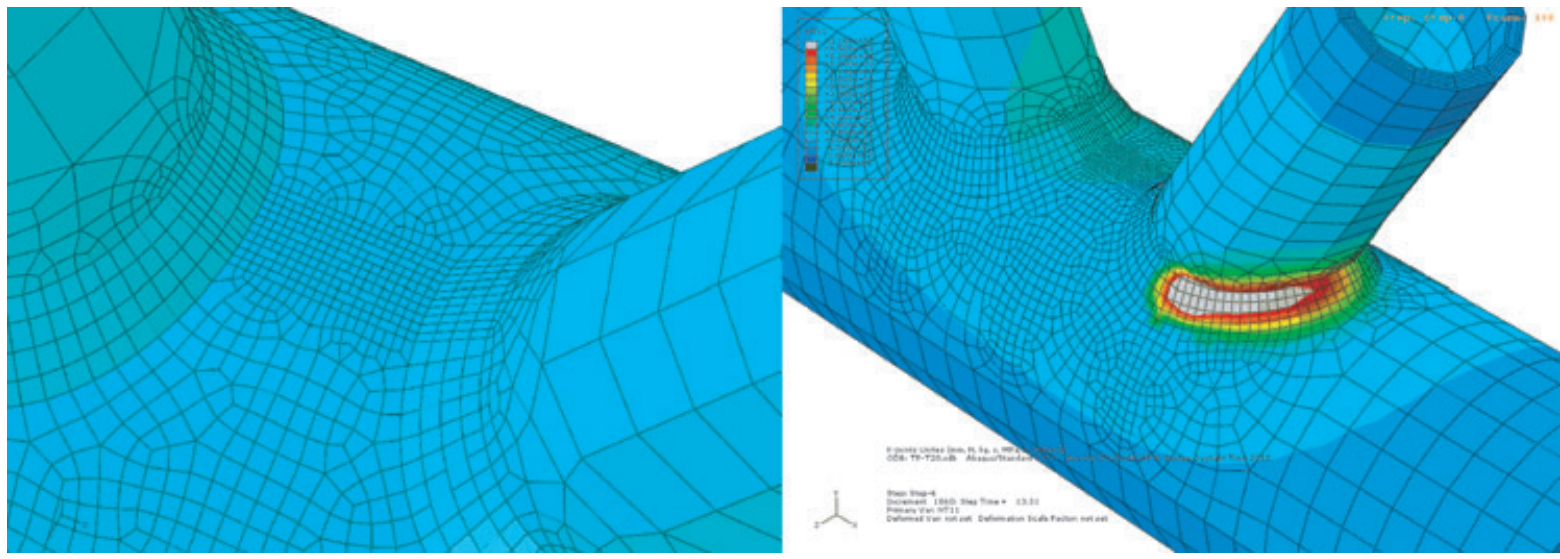

Fig. 4 (Left): Mesh composed of 3D continuum (solid) elements with 8 nodes, (right) temperature distribution during a welding step (light grey area in the weld corresponds to the melted zone, $T \geq 1500^{\circ} \mathrm{C}$ ).

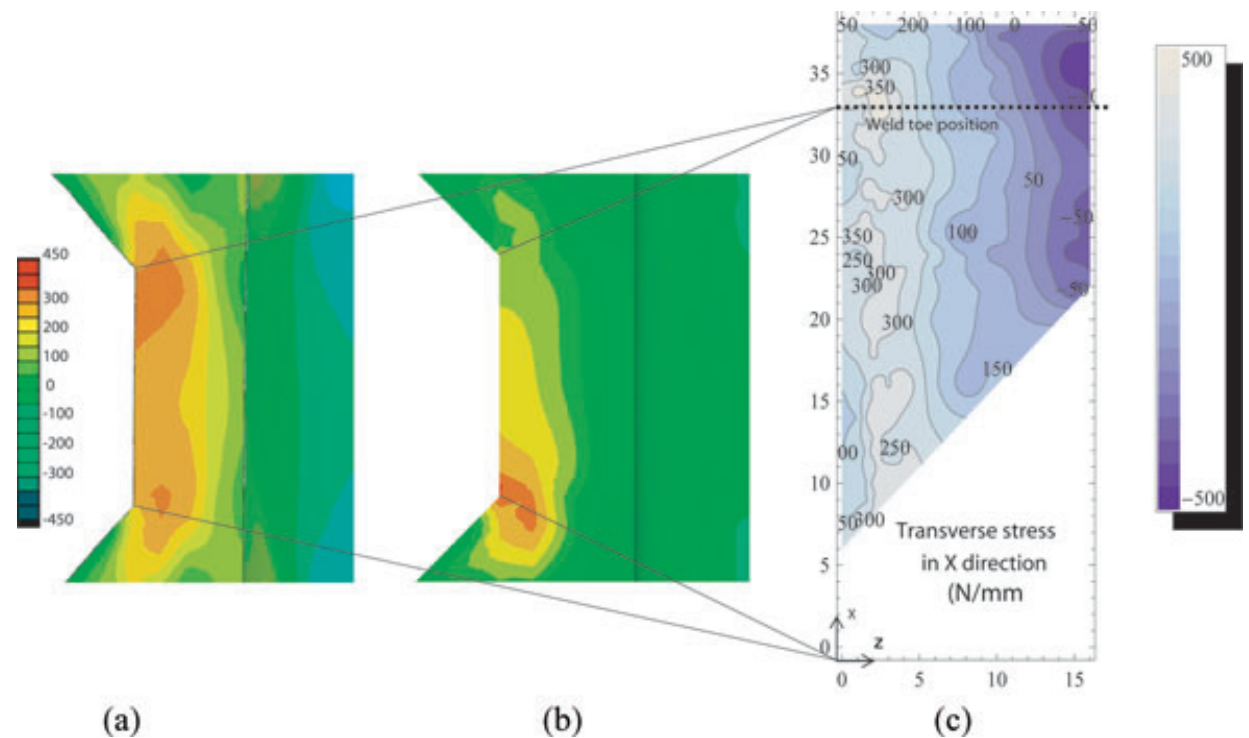

Fig. 5 Residual stress maps representing transverse stress variation in the gap area and through the chord wall thickness: (a) ABAQUS simulation, (b) MORFEO simulation, (c) experimental data. The numerical and experimental stress values are given in MPa.

longitudinal and radial directions. They are not presented herein because they are less interesting with respect to crack propagation but they can be found in Ref. [19]. Note that, they give lower residual stresses in the gap region.

Figure 6 depicts the stress distributions, along a vertical line passing through the $20 \mathrm{~mm}$ chord wall thickness underneath the weld toe. The error in residual stress measurements is reported as a range on each data point. The measurement uncertainty that is quoted in the data sets is derived from the fitting uncertainties in the analysis of the raw neutron data by normal error propagation. Measurements were repeated at the same position to assess the systematic error, the magnitude of which remained lower than the statistical error of the fit. The statistical error is not negligible for stresses measured in the sample of $20 \mathrm{~mm}$ thick because of the long path that the neutron beam has to travel, leading to poor counting statistics (low peak to background ratio).

Experimental results show that residual stress magnitude reaches the yield strength of the $\mathrm{S} 355 \mathrm{~J} 2 \mathrm{H}$ steel at the weld toe (approximately $355 \mathrm{MPa}$ ). At and near the surface, the orientation of greater residual stresses is perpendicular to the weld toe, which is also the orientation of the externally applied stresses. This finding has led to a drastically different residual stress orientation than the one found in 


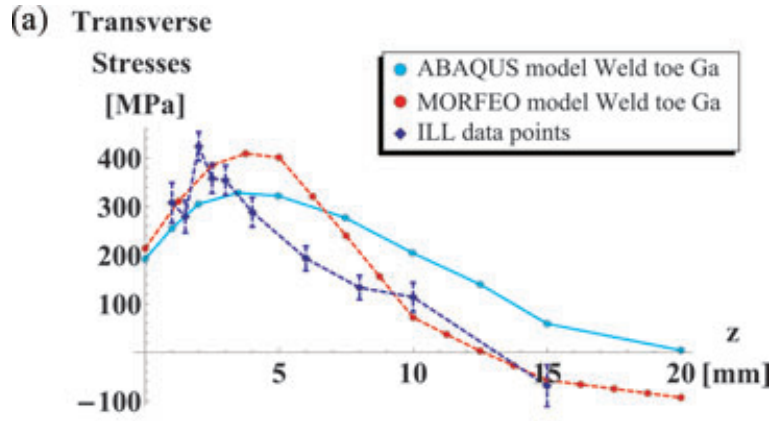

(b) Longitudinal

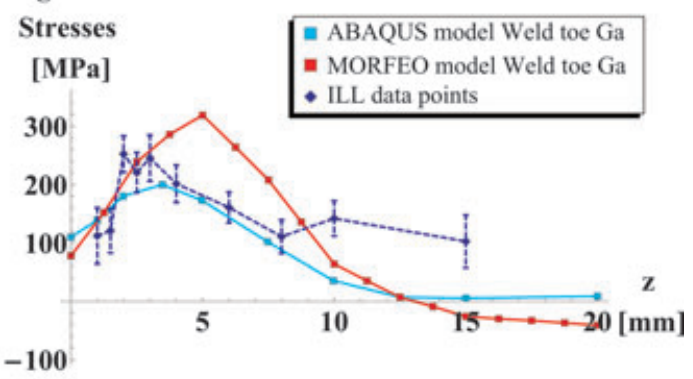

(c) Radial

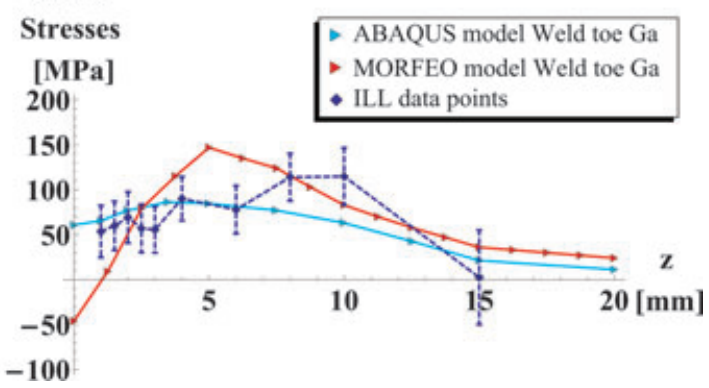

Fig. 6 Comparison of transverse (a), longitudinal (b) and radial (c) residual stress distributions (ABAQUS, MORFEO and neutron-diffraction data obtained at the Institut Laue-Langevin; ILL) for a K-joint with $20 \mathrm{~mm}$ chord wall thickness.

the literature ${ }^{30,31}$ or in British Standards $7910^{32}$ for pipe and pressure vessels tubes where residual stresses parallel to the weld direction are dominant.

In addition, Fig. 5(c) gives evidence of the existence of a restraining effect in between the braces composing the joints creating high perpendicular residual stresses in the gap region.

As depicted in Figs 5 and 6, numerical results are in global good agreement with the experimental investigations. The simplified model demonstrated the ability to reproduce residual stress distributions in the region surrounding the welds, even though the peak values were not always well captured and the distribution was sometimes shifted (see Fig. 6). This difficulty to accurately simu- late the peak may be attributed to the simplification of the seven passes into a single one. This numerical result could be improved by reducing the seven passes to three passes as recommended by Dong and Hong ${ }^{21}$ according to a sensitivity analysis of the number of passes needed for the model.

The transverse residual stress distribution obtained with ABAQUS was shifted to the right compared with the experimental distribution. This means that transverse residual stresses should be compressive at $13 \mathrm{~mm}$ depth but the ABAQUS models present tensile residual stresses through all the depth. This phenomenon may be because of an improper consideration of melting latent heat, however the same latent heat has been introduced in both numerical models.

In Fig. 6, it is seen that MORFEO welding reproduces the distribution of transverse residual stress measurements more accurately, whereas the ABAQUS results fit better with the longitudinal stress distribution. The difference between ABAQUS and MORFEO results are difficult to explain as their mesh, the transient heat conduction formulation and the material properties are the same. The difference might be attributed to the different heat source models (sphere versus truncated circular cone) and to the time increment techniques (based on the Newton-Raphson method in ABAQUS and more userdefined in MORFEO).

These results confirmed the residual stress orientation obtained experimentally. They also demonstrate the strong restraining effect that occurs in the gap area, keeping transverse residual stresses at a high value.

The geometry of the K-joint creates both high-applied stresses as well as, high-residual stresses (from welding) which is critical for fatigue. Therefore, with the applied stresses superimposed on the residual stresses, the location and direction of the fatigue crack propagation in the Kjoints can be explained.

\section{PROPOSED RESIDUAL STRESS DISTRIBUTIONS}

A geometric parametric study is performed using the validated thermomechanical FE model in ABAQUS to quantify the influence of joint size (both absolute and nonproportional size effect) on residual stress distribution. A range of dimensional and non-dimensional joint parameters are investigated: $10 \mathrm{~mm}<T<60 \mathrm{~mm}, 0.2<\tau=$ $t / T<0.6,0.53<\beta=d / D<0.64,2.8<\gamma=D / 2 T<$ $8.4,0.3<\zeta=g / D<1$ and brace angles $\theta$ of $60^{\circ}$. Each parameter is studied one by one, the others being kept constants. Table 1 presents the list of parameters used for this study. 
Table 1 Dimensions and parameters defining the parametric joint models

\begin{tabular}{|c|c|c|c|c|c|c|c|c|c|c|c|c|}
\hline & & \multicolumn{6}{|c|}{ Dimensions (mm) } & \multicolumn{5}{|c|}{ Parameters } \\
\hline & & $D$ & $T$ & $d$ & $t$ & Chord length & Brace length & $\beta$ & $\gamma$ & $\tau$ & $g(\mathrm{~mm})$ & $g / D$ \\
\hline \multirow[t]{2}{*}{ Ref. models } & 1 & 168.3 & 20 & 88.9 & 8 & 600 & 350 & 0.53 & 4.21 & 0.4 & 51 & 0.30 \\
\hline & 2 & 168.3 & 30 & 88.9 & 8 & 600 & 350 & 0.53 & 2.81 & 0.27 & 51 & 0.30 \\
\hline \multirow[t]{4}{*}{ Proportional scaling } & 3 & 84 & 10 & 45 & 4 & 600 & 350 & 0.53 & 4.2 & 0.4 & 26 & 0.31 \\
\hline & & 168.3 & 20 & 88.9 & 8 & & & 0.53 & 4.21 & 0.4 & 51 & 0.30 \\
\hline & 4 & 244.5 & 30 & 127 & 12.5 & 750 & 750 & 0.52 & 4.08 & 0.42 & 79 & 0.32 \\
\hline & 5 & 505 & 60 & 268 & 24 & 1200 & 700 & 0.53 & 4.2 & 0.4 & 155 & 0.31 \\
\hline \multirow[t]{11}{*}{ Non-proportional scaling } & 6 & 168.3 & 20 & 88.9 & 4 & 600 & 350 & 0.53 & 4.21 & 0.2 & 45 & 0.26 \\
\hline & & 168.3 & 20 & 88.9 & 8 & & & 0.53 & 4.21 & 0.4 & 51 & 0.30 \\
\hline & 7 & 168.3 & 20 & 88.9 & 12 & 650 & 400 & 0.53 & 4.21 & 0.6 & 58 & 0.34 \\
\hline & 8 & 168.3 & 20 & 108 & 8 & 650 & 400 & 0.64 & 4.21 & 0.4 & 51 & 0.30 \\
\hline & & 168.3 & 20 & 88.9 & 8 & & & 0.53 & 4.21 & 0.4 & 51 & 0.30 \\
\hline & 9 & 168.3 & 30 & 88.9 & 12.5 & 650 & 400 & 0.53 & 2.81 & 0.42 & 58 & 0.35 \\
\hline & & 168.3 & 20 & 88.9 & 8 & & & 0.53 & 4.21 & 0.4 & 51 & 0.30 \\
\hline & 10 & 168.3 & 10 & 88.9 & 4 & 600 & 350 & 0.53 & 8.42 & 0.4 & 45 & 0.26 \\
\hline & & 168.3 & 20 & 88.9 & 8 & & & 0.53 & 4.21 & 0.4 & 51 & 0.30 \\
\hline & 11 & 168.3 & 20 & 88.9 & 8 & 650 & 400 & 0.53 & 4.21 & 0.4 & 91 & 0.54 \\
\hline & 12 & 168.3 & 20 & 88.9 & 8 & 750 & 500 & 0.53 & 4.21 & 0.4 & 168 & 1.00 \\
\hline
\end{tabular}

Note: The reference modelled geometries Ref-T20 and Ref-T30 are presented in grey.

The welding power $Q$ is calculated for each configuration as a function of the weld geometry. The volumetric heat source $s$ is supposed to be identical to the one used to weld the joint presented in chapter $2(s=5.87 \mathrm{~W}$ $\mathrm{mm}^{-3}$ ) for each weld size. The welding power is then defined as $Q=s . V$, where $V$ is the volume of the spherical heat source heating the material. The spherical volume is directly proportional to the cube of the weld size. To be consistent, the type of FE and the mesh size are kept identical for all the models.

Based on these computed results, distributions of transverse, longitudinal and radial residual stresses are proposed in Eqs (1)-(3) in the form of third-order polynomial equations. These equations are only suitable for $\mathrm{K}$-shape joints in mild steel welded with a metal active gas arc welding process and within the range of validity given above. They are given in MPa along a vertical line that starts from the weld toe and penetrates in depth.

Particularly relevant for $\mathrm{K}$-joint design, the magnitude of tensile transverse residual stresses is strongly increased by a raise of $T$ (in proportional scaling) or/and $\tau$ (in non-proportional scaling). In previous studies by Borges, ${ }^{33}$ the same parameters were also shown to reduce the fatigue strength under applied loads. These parameters have a combined effect on residual stresses and applied loads influencing the fatigue strength of K-joints.
Note that, $\beta$ and $\gamma$ strongly influence the longitudinal and radial residual stress magnitudes. A raise of these parameters induces an increase of longitudinal and radial residual stresses.

$$
\begin{aligned}
\sigma_{\text {res, tr }}= & \frac{1}{\left(\frac{\zeta}{(\zeta)}\right)^{0.15}}\left[300 \frac{\left(\frac{T}{T_{0}}\right)^{0.3}\left(\frac{\tau}{\tau_{0}}\right)^{0.4}}{\left(\frac{\beta}{\beta_{0}}\right)^{0.25}}\right. \\
& -300 \frac{\left(\frac{\beta}{\beta_{0}}\right)^{4}\left(\frac{\gamma}{\gamma_{0}}\right)^{1.6}}{\left(\frac{T}{T_{0}}\right)^{0.5}\left(\frac{\tau}{\tau_{0}}\right)^{1.5}}\left(\frac{z}{T}\right)^{2} \\
& \left.+60 \frac{\left(\frac{\beta}{\beta_{0}}\right)^{8}\left(\frac{\gamma}{\gamma_{0}}\right)^{2.5}}{\left(\frac{T}{T_{0}}\right)^{1.2}\left(\frac{\tau}{\tau_{0}}\right)^{3}}\left(\frac{z}{T}\right)^{3}\right], \\
\sigma_{\text {res, long }}= & \left(\frac{\zeta}{(\zeta)_{0}}\right)^{0.25}\left(\frac{T}{T_{0}}\right)^{0.25}\left(\frac{\gamma}{\gamma_{0}}\right)^{0.9} \\
& \times\left[125 \frac{\left(\frac{\beta}{\beta_{0}}\right)^{3.2}}{\left(\frac{\tau}{\tau_{0}}\right)^{0.9}}-470 \frac{\left(\frac{\beta}{\beta_{0}}\right)^{2}}{\left(\frac{\tau}{\tau_{0}}\right)^{1.65}}\left(\frac{z}{T}\right)^{2}\right. \\
& +270 \frac{\left(\frac{\beta}{\beta_{0}}\right)^{2.6}}{\left.\left(\frac{\tau}{\tau_{0}}\right)^{2.2}\left(\frac{z}{T}\right)^{3}\right],}
\end{aligned}
$$



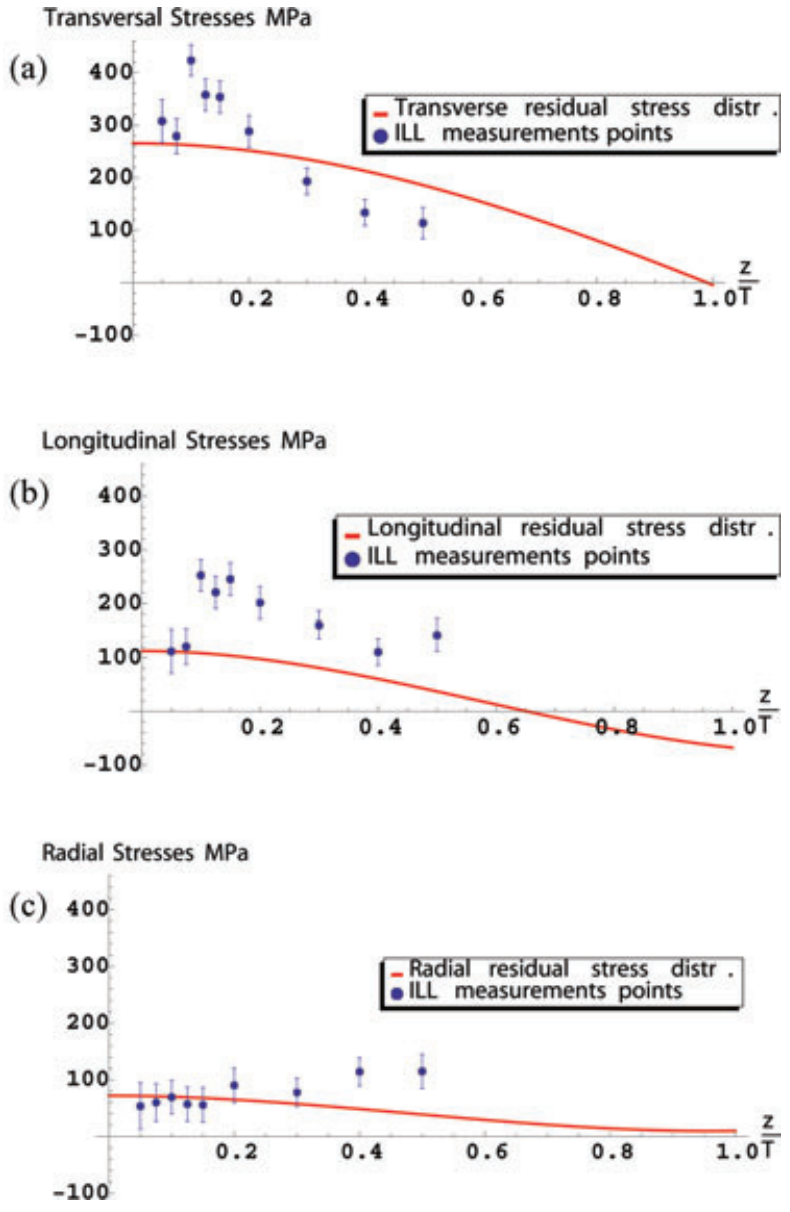

Fig. 7 Comparison of residual stress profiles and experimental measurements obtained at the Institut Laue-Langevin (ILL; mean and covariance values are related to the ratio of experimental to proposed residual stresses).

$$
\begin{aligned}
\sigma_{\text {res, radial }}= & \left(\frac{\beta}{\beta_{0}}\right)^{1.5}\left(\frac{\gamma}{\gamma_{0}}\right)^{0.6}\left[75 \frac{\left(\frac{T}{T_{0}}\right)^{0.1}}{\left(\frac{\tau}{\tau_{0}}\right)^{0.8}}-230 \frac{\left(\frac{T}{T_{0}}\right)^{0.3}}{\left(\frac{\tau}{\tau_{0}}\right)^{1.4}}\right. \\
& \left.\times\left(\frac{z}{T}\right)^{2}+160 \frac{\left(\frac{T}{T_{0}}\right)^{0.3}}{\left(\frac{\tau}{\tau_{0}}\right)^{1.6}}\left(\frac{z}{T}\right)^{3}\right]
\end{aligned}
$$

where the reference geometry values are taken as $T_{0}=$ $30 \mathrm{~mm} ; \tau_{0}=0.4 ; \beta_{0}=0.53$ and $\zeta_{0}=0.3$.

Residual stress profiles are presented in Fig. 7 and compared with residual stress values obtained experimentally at ILL (sample FAT-20). The ratios of experimental values versus proposed profile values are calculated. The average value and the covariance value of these ratios are given in Fig. 7.

These results show that the residual stress profile succeeds to evaluate the global magnitude of transverse stresses, even though the peak value is not captured accurately. For longitudinal and radial stresses, stress profiles are coarse and need to be improved. It is reminded that transverse stress distribution is of the most interest, because principal stresses due to the applied loads and the welding process are both oriented transversely.

Simulating multiple passes leading to an unaffordable computation time for the parametric study, an equivalent single pass was used to represent the seven passes. Therefore residual stress results can be improved by taking into account the multi-pass welding.

(a) Transverse residual stress (Mean $=1.09 ; \mathrm{COV}=12 \%)$,

(b) Longitudinal residual stress $(\mathrm{Mean}=2.05 ; \mathrm{COV}=$ $66 \%$ and

(c) Radial residual stress $(\mathrm{Mean}=1.36 ; \mathrm{COV}=61 \%)$.

\section{CONCLUSIONS}

This study explains why tubular K-joints and especially the gap region of these joints are so sensitive to fatigue loading. Residual stress distributions based on experimental measurements (neutron-diffraction) and numerical results (ABAQUS and MORFEO codes) are given in this paper. Analytical equations for residual stress distributions with depth are proposed at the critical fatigue locations.

Main conclusions of this paper are the following:

- The database of 3D residual stress results, obtained by neutron-diffraction in thick specimen using the modern equipment of the Institute Laue-Langevin (spallation reaction and nuclear reaction), is a valuable source of information. It is shown from these measurements that welding induces high tensile residual stresses particularly in the direction perpendicular to the weld. These stresses reach the yield strength of the $\mathrm{S} 355 \mathrm{~J} 2 \mathrm{H}$ steel at the weld toe. The geometry of the $\mathrm{K}$-joint creates, in addition to high transverse residual stresses, high transverse applied stresses, which are critical for fatigue.

- The 3D thermomechanical model is able to accurately reproduce residual stresses with reduced computational complexity and computing time, especially by considering only one equivalent weld pass. Numerical results are in good agreement with experimental results obtained from neutron-diffraction. MORFEO gives the best estimation of transverse residual stress distribution and ABAQUS provides the best estimation of longitudinal residual stress distribution.

- Based on a geometric parametric study carried out with ABAQUS, residual stress distributions with depth at the critical fatigue locations are proposed. They provide designers with the main trends of residual stresses corresponding to joint geometry. It is found that the magnitude of tensile transverse residual stresses of interest is strongly increased by a raise of the chord thickness $T$ (in proportional scaling) or/and $\tau$ (in non-proportional scaling). In previous studies, the same parameters were also shown to 
reduce the fatigue strength under applied loads. These parameters have a combined effect on residual stresses and applied loads which influence detrimentally the fatigue strength of K-joints.

\section{Acknowledgements}

This research was supported by the Swiss National Science Foundation (SNF). The tubes used for experiments were supplied by Vallourec and Mannesmann Deutschland $\mathrm{GmbH}$ within the framework of the FOSTA project $\mathrm{P} 591$. The welded $\mathrm{K}$-joints and the large-scale truss beams were fabricated by Zwahlen and Mayr S.A. (Aigle, Switzerland). The authors would like to thank Dr. A. Evans and Dr. D.J. Hughes for their help during neutrondiffraction experiments at the Institute Laue-Langevin (SALSA), respectively.

\section{REFERENCES}

1 Zhao, X. L., Herion, S., Packer, J. A., Puthli, R., Sedlacek, G., Wardenier, J., Weynand, K., van Wingerde, A. M. and Yeomans, N. F. (2000) Design guide for circular and rectangular hollow section joints under fatigue loading. CIDECT, TUV-Verlag GmbH, Germany.

2 Schumacher, A. and Nussbaumer, A. (2006) Experimental study on the fatigue behaviour of welded tubular K-joints for bridges. Eng. Struct. 28, 745-755.

3 Nussbaumer, A. and Borges, L. (2008) In: Experimental determination of stress intensity factors on large-scale tubular trusses fatigue tests (Edited by Y. Y. Chen, Z. Y. Shen, and X. Z. Zhao), Taylor \& Francis, Vol. 12, Shangai, China, 8-10 October, 351-358.

4 Marshall, P. (1992) Design of welded tubular connections, Basis and use of AWS provisions. Elsevier Science Publishers, Amsterdam, Netherlands.

5 Romeijn, A., Puthli, R. S. and Wardenier, J. (1993) In: Guidelines to the numerical determination of stress concentration factors of tubular joints (Edited by M.G. Coutie and G. Davies), E \& FN Spon, Vol. 5, Nottingham, U.K., 25-27 August, 625-639.

6 API (2000) Recommended practice for planning, designing and constructing fixed offshore platforms. API Recommended Practice 2A (RP2A), $21^{\text {st }}$ edition, Washington, USA.

7 Withers, P. J. (2007) Residual stress and its role in failure. Rep. Prog. Phys., 70, 2211-2264.

8 Smith, I. F. C. and Smith, R. A. (1982) Defects and Crack Shape Development in Fillet Welded Joints. Fat. Ing. Mater. Struct. 5 (2), 151-165.

9 Barsoum, Z. and Samuelsson, J. (2006) Fatigue assessment of cruciform joints welded with different methods. Steel Res. Int. 77 (12), 882-888.

10 Gurney, T. R. (1979) Fatigue of welded structures (2 ${ }^{\text {nd }}$ ed.). Cambridge Univ. Press, New York, U.S.A.

11 McClung, R. C. (2006) A literature survey on the stability and significance of residual stresses during fatigue. Fatigue Fract. Engng Mater. Struct. 30, 173-205.

12 James, M. N., Hughes, D. J., Chen, Z., Lombard, H., Hattingh, D. G., Asquith, D., Yates, J. R. and Webster, P. J. (2007) Residual stresses and fatigue performance. Eng. Fail. Anal. 14, 384-395.
13 Radaj, D., Sonsino, C. M. and Flade, D. (1998) Prediction of service fatigue strength of a welded tubular joint on the basis of the notch strain approach. Int. F. Fatigue 6, 471-480.

14 Gurney, T. R. (1977) In: Some recent work relating to the influence of residual stresses on fatigue strength. The Welding Institute, Cambridge, England, 15-17 November, 151-163.

15 Hughes, D. J., Bruno, G., Pirling, T. and Withers, P. J. (2006) First impressions of SALSA: the new engineering instrument at ILL. Neutron News 17 (3), 28-32.

16 Fitzpatrick, M. E. and Lodini, A. (2003) Analysis of residual stress by diffraction using neutron and synchrotron radiation, Taylor \& Francis, London, U.K.

17 Webster, G. (2001) Polycrystalline Materials: Determination of Residual Stresses by neutron Diffraction, ISO/TTA 3. International Organization for Standardization, Geneva, Switzerland.

18 AWS A5.20/A5.20M (2005) Specification for carbon steel electrodes for flux cored arc welding. American National Standards Institute/ American Welding Society ANSI/AWS.

19 Acevedo, C. and Nussbaumer, A. (2012) Effect of tensile residual stresses on fatigue crack growth and $\mathrm{S}-\mathrm{N}$ curves in tubular joints loaded in compression. Int. F. Fatigue 36, 171-180.

20 Acevedo, C., Evans, A. and Nussbaumer, A. (2012) Neutron diffraction investigations on residual stresses contributing to the fatigue crack growth in ferritic steel tubular bridges. Int. 7 . Pres. Ves. Pip., avalarle online: http://dx.doi.org/10.1016/j.ijpvp.2012.05.004.

21 Dong, P. and Hong, J. K. (2002) Recommendations for determining residual stresses in fitness-for-service assessment. WRC bulletin 476 (ISBN: 1-58145-483-X).

22 Lindgren, L. E. (2001) Finite element modeling and simulation of welding, Part1: Increasing complexity. Fournal of Thermal Stresses 24, 141-192.

23 Raymond, L. O. and Chipman, J. (1967) Thermodynamic functions of iron. Trans. Met. Soc. AIME 239, 630-633.

24 EN1993 (2005) Eurocode 3: Design of Steel structures-Part 1-2: General rules - Structural fire design. Brussels: European Committee for Standardization.

25 Michaleris, P. (2011) Online Courses at the Pennsylvania State University.

26 Papazoglou, V. J. and Masubuchi, K. (1982) Numerical-analysis of thermal-stresses during welding including phase-transformation effects. 7. Press. Vess. - T. ASME 104 (3), 198-203.

27 Goldak, J., Chakravarti, A. and Bibby, M. (1984) A new finite-element model for welding heat-sources. Metall. Trans. B 15B (2), 299-305.

28 Abaqus (2009) Analysis user's manual version 6.9, Dassault Systèmes Simulia Corp., Providence, U.S.A.

29 Morfeo (2009) v1.3 user manual, Cenaero, Gosselies, Belgium.

30 Stacey, A., Barthelemy, J.-Y., Leggatt, R. H. and Ainsworth, R. A. (2000). Incorporation of Residual Stresses into the SINTAP Defect Assessment Procedure, Eng. Fract. Mech. 67 (6), 573-611.

31 Leggatt, R. H. (2008). Residual stresses in welded structures. Int. F. Pres. Ves. Pip. 85, 144-151.

32 BS 7910 (1999) Guide on methods for assessing the acceptability of flaws in metallic structures. British Standard Institute, U.K.

33 Borges, L. C. (2008) Size Effects in the Fatigue Behaviour of Tubular Bridge Joints. PhD Thesis EPFL 4142, Ecole Polytechnique Fédérale de Lausanne, Lausanne, Switzerland. 